\title{
Can regenerative medicine save Big Pharma’s business model from the patent cliff?
}

The patent cliff is upon us, resulting in the expiry of patents for many blockbuster drugs. Pharmaceutical companies are on the lookout for ways to refill their pipelines. Is regenerative medicine the solution for Big Pharma?

KEYWORDS: disruptive $\approx$ patent cliff $₫$ pharmaceutical $\approx$ stem cell

\section{What is the patent cliff?}

Subject to any regulatory protections, such as data exclusivity, orphan drug designation or supplementary protection certificates, once a pharmaceutical loses patent protection, competitors are free to sell generic copies of the drug. Ordinarily, this results in a dramatic loss of market share and/or profitability. The European Commission's Pharmaceutical Sector Inquiry reported that 2 years after the launch of a generic medicine, prices declined by an average of $40 \%$. However, the price reduction can be as drastic as an $80 \%$ reduction in sales.

A number of highly significant pharmaceutical patents are likely to expire in 2011 and 2012. Patents that underpin a huge proportion of the current sales revenue made by pharmaceutical companies will expire in the next few years. This is known as the 'patent cliff'. These involve blockbuster drugs (i.e., those that achieve annual sales in excess of US $\$ 1$ billion) such as Lipitor ${ }^{\circledR}$, Plavix $^{\circledR}$, Advair ${ }^{\circledR}$ and Seroquel ${ }^{\circledR}$. For some companies, these products will be the largest or second largest selling products. Datamonitor estimates that "the impending 2011 patent cliff ... is set to erode $\$ 78$ billion in global branded sales from drugs facing patent expiry over the 2010-2014 period (plus $\$ 32$ billion from continued erosion of already expired brands)" [1]. Deloitte estimates the erosion brought about by the patent cliff at $\$ 60$ billion for drugs going off-patent in 2010 and 2011 [101].

This exacerbates recent patent expiries. It was projected that $\$ 104$ billion would be lost to generic medicines between 2005 and 2010. IMS Health forecasts that $\$ 130$ billion of prescription drugs will come 'off-patent' by 2012, leaving a financial vacuum for those companies where markets will be flooded with 'me too' alternatives [2].
In February 2007, Jean-Pierre Garnier, then Chief Executive of GlaxoSmithKline, stated of the blockbuster model: "This is a business model where you are guaranteed to lose your entire book of business every 10-12 years. The first reflex of companies is to merge and that buys them a little time to deal with patent expiries, but fundamental changes will ultimately be necessary" [3].

Traditionally, pharmaceutical companies have sought to replace their blockbusters with new drugs from their pipeline. However, the pipeline is running relatively dry and the $R \& D$ productivity of pharmaceutical companies continues to decline. By way of example, in a PricewaterhouseCoopers $(\mathrm{PwC})$ report with analysis based on data from the US FDA/CDER and PhRMA data, in 1996, PhRMA members spent approximately $\$ 16$ billion on $R \& D$ and the FDA approved 55 products (new molecular entities and biologics). By contrast, in 2007, the expenditure had more than tripled to $\$ 55$ billion, while only 19 products were approved. In 2008, the cost (including the cost of failed drug candidates) of bringing each new drug to market was estimated at more than $\$ 1$ billion [4]. This has been exacerbated by high-profile failures such as torcetrapib, which Pfizer was hoping would replace Lipitor [5].

Consequently, pharmaceutical companies are urgently seeking new products to refill the pipeline. In 2007, Bristol-Myers Squibb developed the 'String of Pearls' initiative to replenish its portfolio by buying small biotechnology companies or partnering with other researchers and companies [6]. Some commentators described Pfizer's acquisition of Wyeth for $\$ 68$ billion in 2008 as "an act of desperation" to help refill Pfizer's pipeline [7].

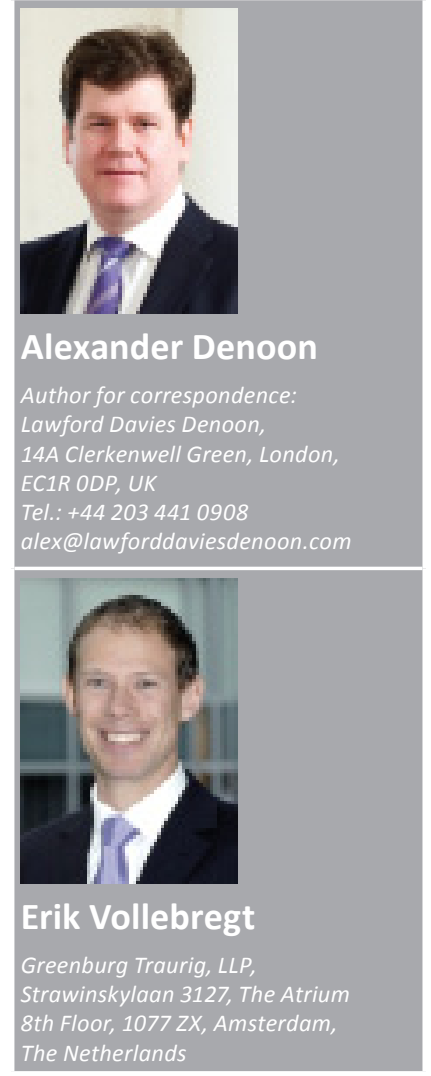

future medicine $^{\text {pos }}$ fs 
In summary, Big Pharma faces unprecedented challenges and is ardently seeking new products.

\section{Can regenerative medicine help?}

The broad field of regenerative medicine ranges from relatively straightforward therapies such as the treatment of specific conditions using autologous cells harvested from the patient, to the treatment of multiple conditions using massproduced allogeneic cells (whether embryonic or adult stem cells).

PricewaterhouseCoopers predicts that regenerative medicine products will come to market in a manner that reflects the complexity of the material itself and the conditions being treated. Thus, PwC anticipates this progression:

- The first products will be treatments for wound care, cartilage and bone injury using differentiated stem cells, biomaterials and growth factors. Some of these products are already on the market, such as Apligraf ${ }^{\circledR}$ by Organogenesis and more recently the ChondroCelect ${ }^{\circledR}$ cartilage product manufactured by TiGenix that was approved by the European Medicines Agency (EMA) in October 2009;

- The second wave will be treatments for conditions such as mycocardial infarct and diabetes using adult stem cells, such as the products being developed by Advanced Cell Technology, Bioheart Inc., Cardio3 Biosciences, Cytori Therapeutics Inc. and Gaminda Cell Ltd;

- Treatments for the CNS using embryonic stem cells, including products developed by CellCure, Geron, NeuralStem and International Stem Cell Corporation. Obviously, this will extend to a wide variety of conditions if the technology meets expectations.

Clearly, regenerative medicine could have the potential to cure a wide variety of conditions and disorders.

While it is difficult to generalize about all regenerative medicines, common elements make them potentially disruptive. First, unlike many existing products and therapies, regenerative medicine offers the potential to be regenerative rather than merely palliative or symptomatic treatment. This allows therapeutic outcomes that were previously impossible to be achieved. In addition, regenerative medicine offers the prospect of fewer serious side effects than existing products and therapies because it uses existing processes in human biochemistry.
Second, there are many conditions for which there is no current treatment. This is particularly the case with aging-related diseases and complex multifactorial conditions. In fact, some commentators argue that traditional new chemical entities have reached the limit of their usefulness as standalone therapies for a variety of multifactorial conditions. While such predictions may be premature, regenerative medicine offers the potential of treatment for difficult conditions.

Third, as a result of the regenerative nature of the therapies, they are extremely attractive to patients, insurers and public health bodies, public hospitals and palliative care centers. Furthermore, for conditions with no meaningful or appropriate treatment, regenerative medicines are unlikely to cannibalize existing sales by Big Pharma companies.

\section{"Patents that underpin a huge proportion of the current sales revenue made by pharmaceutical companies will expire in the next few years. This is known as the "patent cliff'."}

Fourth, regenerative medicine could change the conventional reliance on patents and their finite exclusivity. An allogeneic cell bank may be able to deliver therapeutic outcomes for a variety of conditions. The owner of the cell lines can control access to and commercialization of the cell lines, irrespective of the patent position. Given the challenges experienced by follow-on biologics, there is a real prospect that it will be very difficult to register a different cell line as a follow-on product based on an existing marketing authorization.

There is strong demand for regenerative medicine from patient groups because many of the diseases that regenerative medicine currently aims to treat are orphan diseases or diseases that cannot be cured with conventional small molecule-based medicinal products. There is broad acceptance in the general public of these potential therapies; since 2002, Gallup polls have consistently shown that more than $50 \%$ of the US public support medical research using stem cells obtained from human embryos [102]. It is accepted within the industry that if regenerative medicine can achieve the projected therapeutic outcomes and overcome the various regulatory hurdles, then it is likely to have a profound impact on the healthcare industry. In 2009, PwC predicted that the market for stem cell products would grow to between $\$ 3$ and 21 billion in 2015 [8]. 


\section{Perfect match}

The regenerative medicine sector requires Big Pharma's insights, skills and experience to assist with commercialization on a larger scale. These skills include regulatory matters; quality control; production on a large scale; distribution and logistics; structuring and conducting clinical trials; and reimbursement and lobbying. The regenerative medicine sector also requires access to funding and resources for the protracted procedures that will be necessary to resolve the remaining ambiguities with respect to patent protection for regenerative medicine-related intellectual property [103]. This is particularly important in light of a decision in November 2008 by the European Patent Office's Enlarged Board of Appeal to revoke a patent describing a method for obtaining embryonic stem cell cultures from primates, including humans. It is worth noting that the Enlarged Board of Appeal stated that this did not concern the general question of patentability of human stem cells. In addition, and not unimportantly, a marriage between a regenerative medicine company and Big Pharma can help a regenerative medicine company avoid folding simply because of the posteconomic crisis lack of funding, with venture capital and public funding dried up. Indeed, some analyses suggest that $25 \%$ of biotech companies have less than 1 year's cash on hand [104]. Two-thirds of biotech executives say that the most important sources of capital have been hit hard by the recession, particularly angle investment, venture capital funding and equity, while the Intellectual Property Office market has also dried up [101].

\section{"Regenerative therapies could help the pharmaceutical industry to recover its reputation at a time when it also faces increased scrutiny from competition authorities."}

In turn, regenerative medicine can help Big Pharma in drug discovery by providing cell lines that help elucidate personalized medicine, genetic variation and what biomarkers to pursue. Furthermore, regenerative medicine could help Big Pharma to gain access to a quickly growing market for new therapies and provide it with new scientific talent.

Thus, a union of regenerative medicine with Big Pharma should be a perfect marriage, whether this takes place through in-licensing, alliances or acquisitions, because both need each other more than ever. Big Pharma needs new ideas, regenerative medicine needs capital and a safe haven in which to leverage science to products.

\section{Evidence of Interest}

McKernan et al. have prepared a summary of Big Pharma investments in regenerative medicine, including Pfizer, Novartis, Roche, Sanofi Aventis, Johnson \& Johnson, Amgen, Novo Nordisk, Teva, Medtronic and Smith \& Nephew [9]. Along similar but parallel lines, it is interesting to note the investment that GE Healthcare has made in the field and its partnership with Geron to use stem cell products for drug discovery [10]. However, as the authors note, while pharmaceutical companies have already commenced using stem cells as research tools, there remains some reluctance to invest heavily in the more radical stem cell-based allogeneic medicines [11].

\section{"Big Pharma faces unprecedented challenges and is ardently seeking new products."}

The sector has recently received boosts from the approval of two new treatments. The EMA approved ChondroCelect as the first stem cellbased advanced therapy medicinal product in October 2009 and the FDA approved Dendreon's autologous prostate cancer vaccine in April 2010. Note that the price of the vaccine will be $\$ 93,000$ for a three-infusion course [11].

It is axiomatic that products that match the above profile are attractive to pharmaceutical and biotech companies, given the pressures that they face. However, the industry is nascent and there is very little clarity with regards to matters as basic as the regulatory pathway. Earlier this year, the EMA issued a reflection paper on stem cell-based medicinal products, seeking input from industry regarding a variety of issues including quality, characterization, dosage, purity, biomarkers, animal models and tumorigencity [105]. Furthermore, the intellectual property position is opaque (especially for embryonic stem cells) and there is no certainty regarding reimbursement models.

\section{Conclusion}

While it would be naive to suggest that regenerative medicine is the answer to Big Pharma woes or even that it could provide blockbuster products by 2012 (when the patent cliff hits), it has features that make it attractive to Big Pharma at this juncture due to its complementary nature to Big Pharma's small molecule products. Principal among these features is the potential to regenerate diseased or affected tissues.

Clearly all interested parties (payers, patients, clinicians, pharmaceutical companies and hospitals) are seeking products that prevent or cure 
conditions rather than merely offer symptomatic or palliative treatment. This is particularly attractive for untreated conditions. However, there is also pressure on healthcare budgets; both public and private payers. Current growth rates of expenditure on pharmaceuticals and healthcare cannot continue on the current trajectory. As a result, there is an increasing interest in therapies that may prevent and/or cure conditions.

Regenerative therapies could help the pharmaceutical industry to recover its reputation at a time when it also faces increased scrutiny from competition authorities.
In our view, regenerative medicine is one of the few technologies that offers the potential to revolutionize healthcare and save Big Pharma's business model.

\section{Financial \& competing interests disclosure}

The authors have no relevant affliations or financial involvement with any organization or entity with a financial interest in or financial conflict with the subject matter or materials discussed in the manuscript. This includes employment, consultancies, honoraria, stock ownership or options, expert testimony, grants or patents received or pending, or royalties.

No writing assistance was utilized in the production of this manuscript.

\section{Bibliography}

1 Pharmaceutical Key Trends 2010 - The Patent Cliff Dominates but Growth Opportunities Remain. Datamonitor 17th March, 259 (2010).

2 All together now - liberalisation and the quest for scale are pushing generic-drug firms to merge. The Economist 24th July, 65-66 (2008).

3 Phelps K: Mergers may buy time, but fundamental changes necessary, GSK's Garnier The Pink Sheet 26th February, 11 (2007).

4 Jack A: Balancing Big Pharma's books. BMJ 336, 416-419 (2008).

5 Berenson A: Pfizer ends studies on drug for heart disease. New York Times 3rd December (2006).

6 Singer N: Bristol-Myers's heavy reliance on 3 drugs puts its prospects for growth in doubt. New York Times 28th January (2009).
7 Miller H: Pfizer weds Wyeth. Forbes 27th January (2009).

8 The New Science of Personalised Medicine: Translating the Promise into Practice. Pricewaterhouse Coopers LLP, London, UK (2009).

9 McKernan R, McNeish J, Smith D: Pharma's developing interest in stem cells. Cell Stem Cell 6(6), 517-520 (2010).

10 Jack A: GE unit unveils alliance with Geron. Financial Times 30th June (2009).

11 Moss A, Smith JC: Dendreon's Provenge faces impact of Medicare reimbursement delay as hospitals rethink orders. PharmaWire 8th July (2010).

\section{Websites}

101 Deloitte: The future of the life sciences industries: aftermath of the global recession www.deloitte.com/assets/Dcom-Global/
Local\%20Assets/Documents/ LSHC/ $2010 \% 20$ Future $\% 20$ of $\% 20$ the $\% 20$ life $\% 20$ sciences $\% 20$ industries $\% 20$ report_web.pdf

102 Gallup polls www.gallup.com/poll/21676/Stem-Cell\%20 Research.aspx

103 The IPKat: Bundesgerichtshof refers human stem cell patent case to ECJ http://ipkitten.blogspot.com/2009/11/ bundesgerichtshof-refers-human-stem.html

104 Life Sciences Tribune 4-5 June (2010) www.deloitte.com/view/en_GX/global/ industries/life-sciences-health-care/46ac2735 c3a38210VgnVCM200000bb42f00aRCRD. htm

105 Reflection Paper On Stem Cell-Based Medicinal Products. European Medicines Agency, London, UK (2010) www.eahp.eu/News/Our-News/Reflectionpaper-on-stem-cell-based-medicinal-products 